\title{
FORMULĂRI STILISTICE ÎN ARHITECTURA TIMIȘOAREI ȘI VÂRȘEȚULUI (SEC. XVIII-XX). STUDIU DE CAZ: PALATELE PRELAȚILOR ORTODOCŞI SÂRBI
}

\begin{abstract}
Propunem o paralelă stilistică între două monumente cu o evoluție seculară în care formulări specifice perioadei istorice în care au fost realizate conturează orizontul documentar al genului. Cu un debut al programelor edilitare situat în secolul XVIII şi având deci toate elementele formale ale stilului ce domină manifestările artistice ale perioadei-barocul, construcțiile trec prin secolul de formare a națiunilor și a identităţii naționale în care Romantismul a adus noi adaptări și secolul XX în care noul stil - Secession, emergent din Viena sau Budapesta a găsit adepți din toate mediile sociale, dovadă adaptarea aspectelor formale ale acestuia la edificiile ridicate în orașele imperiului înainte de 1918. Construcțiile palatelor prelaților ortodocși sârbi au fost impulsionate de situația economică prosperă, de gustul format al comanditarului cu o identitate națională puternic afirmată în contextul dezvoltării oraşului modern în paradigme urbanistice central-europene Creații anonime ale secolului XVIII, ambele palate au avut o o evoluție ce le-a transformat în acord cu evoluția stilistică a fiecărei perioade, fiind vorba de un istorism ce transcede limitele cronologice și face apel la valori identitare. Orientările stilistice ce au generat formele acestor palate se adaugă funcțiunilor diferite, pe lângă cea rezidențială pentru prelatul ortodox sârb, acesta fiind adaptat și funcțiunii religioase (cu capelă configurată spaţial după normele răsăritene, dotată cu iconostas ce separă simbolic lumea văzută de cea nevăzută), acesta fiind cazul palatului din Vârșeț sau pe lângă aceste funcțiuni cea de important centru de iradiere a valorilor ortodoxe sârbești în contextul afirmării națiunilor în perioada de efervescență în care se găsea Banatul înainte de primul război mondial, cazul palatului din Timișoara.
\end{abstract}

Cuvinte cheie: palatele episcopale sârbești, Vârșeț, Timișoara, baroc, Seccession, Laszlo Szekely

Inițierea unui studiu comparativ asupra arhitecturii palațiale din mediul ortodox sârb se înscrie în seria valorificării din punct de vedere științific a unui fragment al patrimoniului din Banat ce a cunoscut o evoluție similară în istoria

\footnotetext{
${ }^{1}$ mihaela.vlasceanu@e-uvt.ro

${ }^{2}$-Lucrarea a fost realizată în cadrul proiectului Centrului de Cercetare Științifică a Culturii Sârbilor din România Cercetarea culturii și istoriei Sârbilor din România.
} 
...

acestei provincii cu statut imperial în secolul XVIII, rând pe rând situată în limitele confiniare ale Imperiului Habsburgic, ale Imperiului Austro-Ungar și ale României Mari după 1918, zonă de confluențe în care s-au contopit interese ce au modelat acest teritoriu în consonanță cu modele central europene consacrate, dar şi cu un puternic tradiționalism specific comunităților ortodoxe în care s-au regăsit în această perioadă, deopotrivă sârbii și românii. Ca și în cazul episcopiei romano-catolice ce și-a ridicat un palat impunător pentru a găzdui sediul instituțional mutat de la Cenad la Timișoara în 1731 și comunitatea sârbă după mutarea episcopiei de la Sremski Karlovci a căutat un sens al identităţii prin comandarea unor monumente reprezentative pentru ortodoxie în contextul reafirmării naționalităților.

Repertorizarea monumentelor în stil baroc din Banatul istoric a condus la concluzii ce au făcut obiectul unor studii comparative, în categoria cărora se înscrie și acest demers. Palatele episcopale ortodoxe sârbe din Timișoara și Vârșeț sunt creații baroce din secolul XVIII, constatându-se o evoluție ce le-a transformat în acord cu evoluția stilistică a fiecărei perioade în care au fost reconstruite, fiind vorba de un istorism ce transcede limitele cronologice și face apel la valori identitare $^{3}$. Acest istorism este elementul definitoriu în ipoteza propusă pentru acest studiu, istorism care este conturat de creația arhitectului care a intervenit în consacrarea celor două monumente ca și repere ce găzduiau prelații ortodocși sârbi. De fapt de la intervenția lui Laszlo Szekely la începutul secolului XX, căci despre acest arhitect este vorba, am pornit în investigarea aspectelor formale și a orientărilor stilistice ale celor două monumente, găsind analogii pentru a contura aspectele ce fac din manifestările artistice ale fiecărei perioade istorice, particularități zonale ale periferiei aflate în permanent contact cu centrul.

Date despre formația și parcursul european al arhitectului care a avut cea mai importantă contribuție în conservarea, restaurarea şi transformarea stilistică a acestor palate - Laszlo Szekely sunt furnizate de facsimilele publicate de istoricul de artă Ileana Pintilie, cea care i-a dedicat cel mai complex parcurs istoriografic în bibliografia de specialitate. După terminarea studiilor la Budapesta, Laszlo Szekely este invitat de către primarul Timişoarei Karol Telbisz în anul 1903 să ocupe funcția de arhitect șef al oraşului, funcție pe care o acceptă cu condiția să-și poată exercita profesia în particular, lucru pe care 1-a și făcut în biroul de arhitectură pe care 1-a condus până în 1922, proiectând și realizând numeroase lucrări publice și private în Banatul începutului de secol XX într-un stil eclectic ce îmbină preferințele pentru un decorativism auster, componentă formală a artei dominate de influențele funcţionaliste vieneze.

La debutul carierei de arhitect șef al Timişoarei, Szekely a avut prilejul și talentul de a realiza construcții care să consoneze cu spațiul urban modern,

\footnotetext{
${ }^{3}$ M.Vlăsceanu, Modele identitare ortodoxe în arhitectura barocă din Banat, în volumul Život posvećen traganju za etničkim identitetom - volum omagial dedicat profesorului univ.dr. Mihai Radan, Ed. Universităţii de Vest, Timişoara, 2019, p. 429-441.
} 
definit de un oraș în plină expansiune grefat pe coordonatele funcționalismului, în acest sens trecerea de la oraşul închis specific secolului al XVIII-lea delimitat de zidurile fortificației Vauban, la orașul deschis conturat la sfârșitul secolului al XIX-lea, când pentru a agrementa noile elemente ale urbanismului, și anume tramvaiul electric ce 1-a înlocuit pe cel tras de cai, moment situat în 1892, zidurile de incintă sunt dărâmate și modelul vienez al Ringului se impune prin funcţionalitate și expansivitate. Centrul istoric a Timișoarei situat în interiorul Cetății este augmentat de glacis care face joncțiunea cu bulevarde largi și chiar cu mutarea cursului râului Bega (zona Fabric) pentru a defini spații ample ce vor fi mobilate cu construcții în spiritul epocii, acea fază târzie a Secessionului, caracterizată de o stilizare și geometrizare a liniei care se evidențiază după anul 1908. Celebrul Coup de fouet al primei faze a stilului face loc unei plastici decorative austere specifice fiecărui stil ce formează ansamblul de influențe al eclectismului internațional.

Istoriografia actuală îl poziționează pe Szekely în rândul arhitecților înzestrați cu talent ce a reuşit să contureze prin creația sa o notă de autenticitate locală, cu afinități stilistice și structurale în spațiul central european, dată fiind formația arhitectului. $\mathrm{Cu}$ o carieră ce putea fi orientată după terminarea studiilor la Budapesta către aspectele didactice ${ }^{4}$, Szekely alege să accepte numirea ca arhitect șef al Timișoarei, iar activitatea fecundă pe care o v-a desfăşura în zona Banatului îi atestă calitățile: de la lucrări publice precum case de vamă, cazarma pompierilor din cartierul Iosefin, abatorul orașului, gimnaziul Piariștilor, turbinele, cinematograful de vară, la lucrări particulare (transformarea Băncii centrale a șvabilor, palate (transformarea palatului episcopal sârbesc dintr-un edificiu baroc într-unul Seccession), palatalul episcopal din Vârșeț, edificii alese pentru a ilustra gândirea arhitecturală ca studiu de caz, la acestea adaugându-se și salba de palate de pe Corso (Dauerbach, Szechenyi, Hilt, Lajos) sau cele de pe Surogat - palatul Camerei de Comerț, cea mai autentică transpunere a normelor neoclasice, Băile Hungaria, clădiri de bănci (Banca de Credit, casa de păstrare a acțiunilor), clădirea sindicatului Industrial etc, pentru a menționa doar câteva din cele mai importante realizări în spiritul epocii.

Din această fecundă activitate ce a avut la bază un academism formal și stilistic, ne rețin atenția edificiile realizate la comandă pentru comunitatea sârbească: palatele prelaților ortodocși sârbi din Timișoara și Vârșeț- două monumente reprezentative pentru arhitectura palațială cu antecedente formale în creația barocului central-european. Dacă prototipurile central-europene ne incurajează să observăm în tot ceea ce ține de

\footnotetext{
${ }^{4}$ Profesorul universitar arhitect Cigler Gyozo i-a propus în 1900, la terminarea studiilor de la Budapesta să urmeze o carieră în învățământul superior, ofertă pusă în practică în calitate de asistent al profesorului Școlii Politehnice Regele Jozsef până în 1903, când propunerea edilului Timișoarei îi modifică aspirațiile și evoluția, documentele ce testă acest parcurs fiind publicate sub forma unor facsimile, pentru detalii vezi, I. Pintilie, Documente din arhive particulare contribuind la cunoașterea unui arhitect timişorean de la începutul secolului XX-Laszlo Szekely, în Studii și comunicări, III, Museum Arad, 1996, pp. 202-224.
} 
$\cdots$

norme și forme anumite direcții, la acestea se adaugă la debutul secolului XX, noi valențe stilistice dictate de gustul epocii ce se alinia tendințelor europene în domeniu. Noul stil - Secession, emergent din Viena sau Budapesta a găsit adepți din toate mediile sociale, dovadă adaptarea aspectelor formale ale acestuia la edificiile ridicate în orașele imperiului înainte de 1918. Cele două construcții au fost prilejuite de situația economică prosperă, de gustul format al comanditarului european cu pretenții și obiceiuri galante (baronul Szecheany aducând jocurile de noroc la Timișoara, primul cazinou fiind găzduit de palatul pe care L. Szekelyi î-l construiește pe Corso). Studiul de caz comparativ aduce în atenția cercetătorului istoriei arhitecturii două palate ecleziastice, cu structuri ce răspundeau nevoilor episcopilor sârbi, transformate și adaptate unor decizii ale autorităţii ecleziastice sârbe, de aici și formulele plastice adoptate în acord cu aspirațiile comanditarului (elemente tradiționale).

Secessionul a fost o mișcare de ruptură stilistică, un fenomen asumat de comunitatea europeană avidă de schimbare, o ruptură de tot ceea ce însemna trecutul din perspectiva stilurilor istorice, promovate de academism, breşă către nou, către căutarea unui stil nou - Art Nouveau. Această schimbare s-a produs în domeniul vizual prin impunerea unor norme noi: o reconfigurare a spațiului urban, o libertate compoziţională, abandonarea normelor, refuzul conștient al academismului, monumentalism, sinteza, adevărul în artă, crearea unei arte internaționale - un internaționalism vizibil în edificiile celor două monumente ce configurează prezentul studiu, o adaptare selectivă a valențelor europene.

În Banatul sec. XX, regiune transfrontalieră a imperiului Austro-Ungar, stilul nou ce a exprimat noua mișcare stilistică - Secessionul s-a relevat prin creația unor arhitecți celebri, provenind din centre europene, Odon Lechner și Otto Wagner fiind precursorii noii realități ${ }^{5}$. Laszlo Szekely este cel mai eclectic dintre arhitecții ce au contribuit la reconfigurarea urbanistică a Timișoarei, fiind tributar academismului din prisma formației academice, dar liber să exprime într-un limbaj propriu ruptura cu tradiția și noile aspiraţii ale unei comunităti angrenate pe drumul către europenitate, căci despre acest aspect este vorba când analizăm arhitectura celor două monumente. Dacă în cazul Vârșețului, edificiul și-a păstrat aspectul caracteristic de palat baroc, în cazul palatului din Timişoara, imaginile de epocă sunt dovada metamorfozelor suferite de la stilul baroc spre neoclasicism și Secessionul de factură vieneză. Palatul Episcopal Ortodox Sârb, situat în Piața Unirii din Timișoara, este unul dintre monumentele emblematice în istoria oraşului, având o evoluție stilistică ce îmbină aceleași preferințe pentru stilurile Europei centrale, de la baroc târziu și neoclasic, la refacerea fațadei cu elemente decorative ale Secessionului vienez și decorativismul accentuat de elemente foliacee de factură neo bizantină.

Construit între anii 1745-1748, în timpul episcopului ortodox sârb al Timișoarei, Gheorghie Popovici, palatul prezintă din punct de vedere arhitectural, caracteristici

\footnotetext{
${ }^{5}$ M.Vlăsceanu, Modele identitare ortodoxe în arhitectura barocă din Banat, în volumul Život posvećen traganju za etničkim identitetom - volum omagial dedicat profesorului univ.dr. Mihai Radan, Ed. Universităţii de Vest, Timişoara, 2019, p. 429-441.
} 
ale stilului baroc târziu, clasicizant prin epurarea de decor şi accentul pe elementele de structură, caracter monumental al faţadei, singura articulată plastic cu baluștrii, cornișe în rezalit etc., având inițial un singur etaj. În anul 1906, construcția a fost extinsă pe două străzi, curtea interioară având evidente influențe neogotice, iar fațada a suferit modificări, prin introducerea unor elemente specifice stilului neobaroc, după planurile arhitectului László Székely. În anul 1911 au fost adăugate decorațiuni preluate din arhitectura sârbească. Stema Episcopiei ortodoxe sârbe de Timișoara surmontează intrarea principală delimitată de portalul carosabil. Situat lângă catedrala ortodoxă sârbă, edificiul a rezonat stilistic cu barocul perioadei tereziene, după cum se observă din imaginile de epocă ce surprind aspectul reprezentativ al palatului realizat ca şi alte exemple ale genului din Transilvania, datate mai târziu, dar realizate după planuri emanate de ingineri camerali și arhitecți consacrați, cum este cazul structurilor impozante cu tipologii, proporții echilibrate și decoruri conexe realizate de Franz Anton Hillebrandt la palatul episcopiei romano-catolice din Oradea (1772-1776) şi cel construit pentru un alt potentat local, baronul Samuel von Brukenthal la Sibiu, după planurile arhitectului Anton Erhard Martinelli, cu patru aripi grupate în jurul unei curți dreptunghiulare, cu curte de serviciu și portal carosabil, ca și element definitoriu plastic pe fațadă. Aceeași sinteză de stiluri o întrezărim și la palatul episcopiei romano-catolice din Timișoara, portalul acestuia fiind printre puținele exemple ale genului decorate cu mascheroni și elemente vegetale sau palatul Guvernatorului (azi Muzeul de Artă, 1756, arhitect Jacob Steinlein) cu accentuate tendințe și afinități stilistice ale barocului francez, rațional mai degrabă, adaptat nevoilor comanditarului, în acest caz cu ferestre tip lucarnă la mansardă.

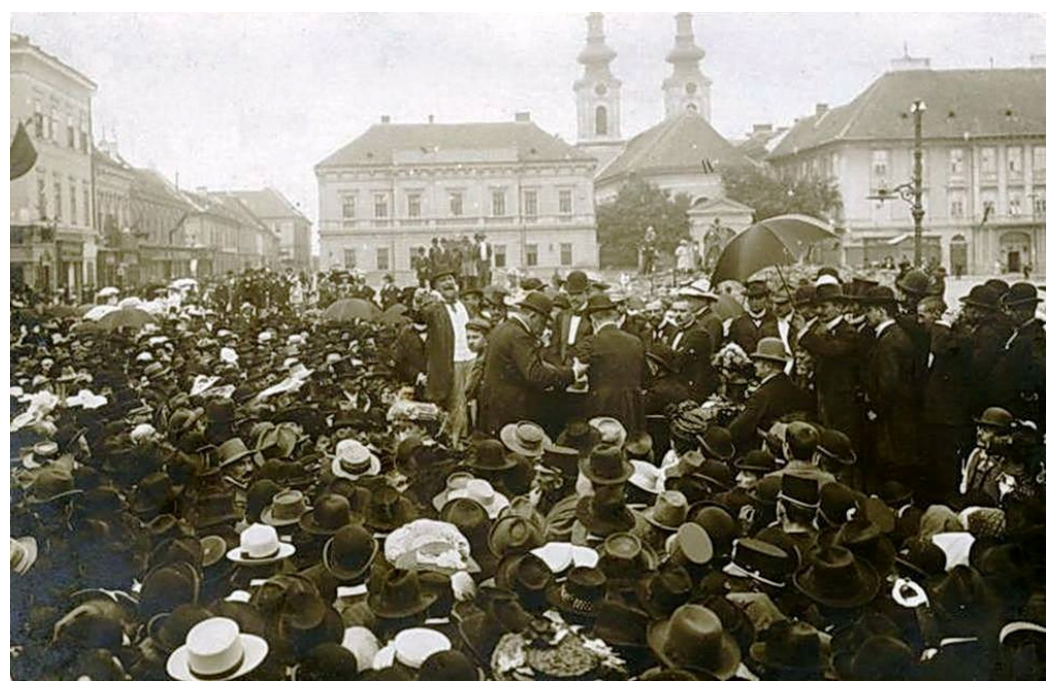

Foto 1. Palatul episcopal sârbesc din Timişoara (Piața Unirii) înainte de reconstrucția fațadei realizată de Laszlo Szekely. (surse Arhiva episcopiei Romano-Catolice din Timişoara, fotografie datată 1903 in perioada alegerilor contelui Apponyi) 


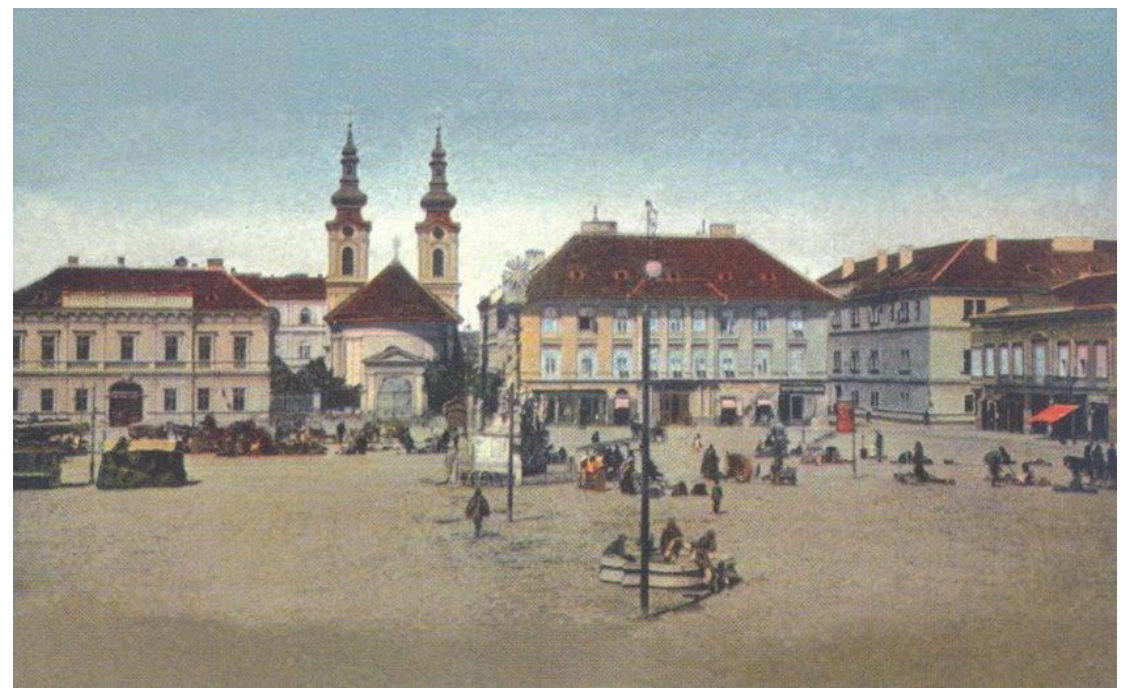

Foto 2. Piața Unirii, înainte de 1905 cu vechea fațadă a palatului epicopal sârbesc specifică barocului târziu clasicizant (apud Arhiva Romano-Catolică din Timișoara)

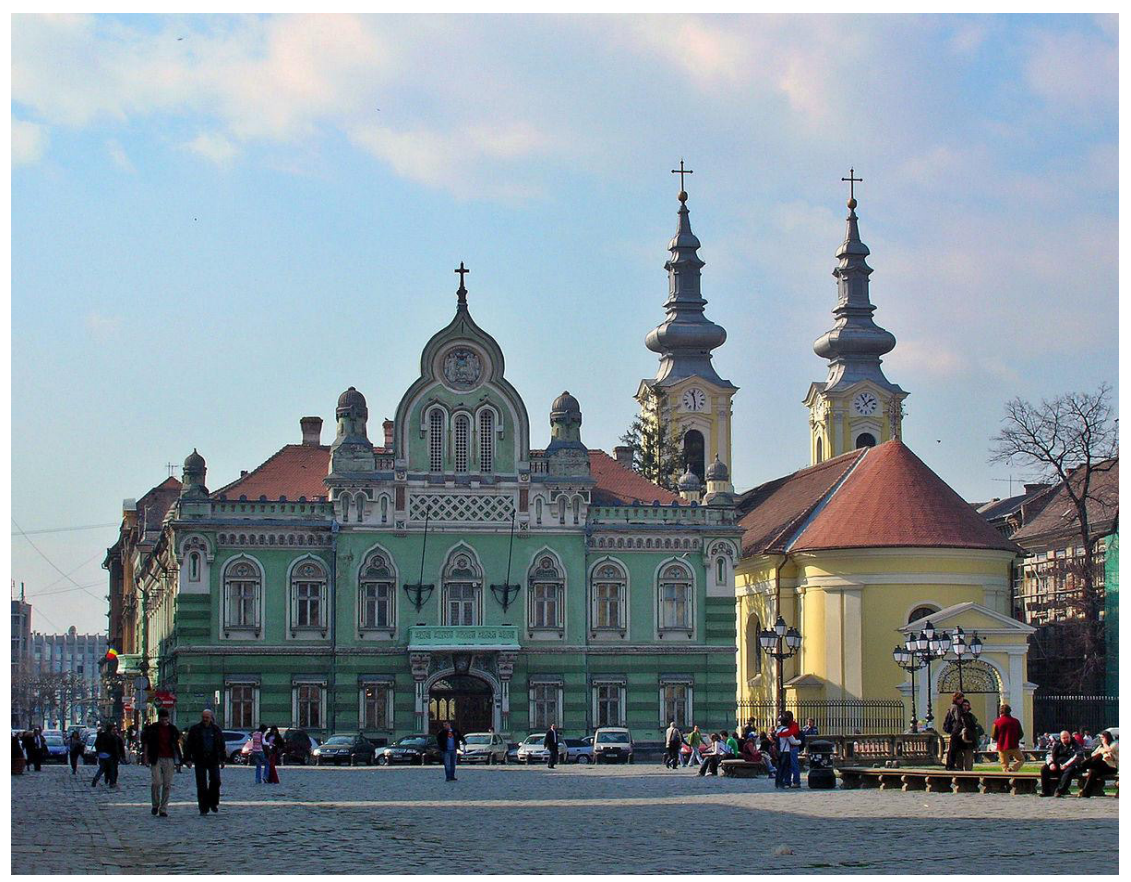

Foto 3. Fațada palatului episcopal sârb din Timișoara realizată de Laszlo Szekely (1904), (surse online apud Voytek S) 
Planurile originale ale palatului pe care a intervenit Szekely în 1904 se păstrează în arhiva Palatului Episcopal Ortodox Sârb. Inițiativa renovării se datorează episcopului Gavrilo Zmejanović, cel care i-a solicitat arhitectului șef al orașului, Laszlo Szekely un proiect grandios, reprezentativ pentru comunitatea sârbă, proiect pe care 1-a și realizat,curtea interioară fiind lărgită, paramentul fiind penetrat de deschiderile ferestrelor modelate după formule ce amintesc de modenaturile goticului, cu arcade frânte, dar și accolade plastice ce articulează dinamic deschiderile, atât pe fațadă, cât și în curtea interioară.

Arhitectura celor două palate iniţiază un dialog formal și stilistic nou, cu valențe eclectice, aspectul național având un rol evident prin elemente de plastică decorativă, subliniind caracterul unei comunități ortodoxe puternice în Banatul începutului de secol XX, cea a sârbilor. Ambele edificii poartă amprenta arhitectului prin structură, dar mai ales prin ceea ce Aleksandar Kadijević consemna ca fiind definitoriu pentru stilul național sârbesc în arhitectură, căutarea unui istorism ancorat în trecut, în valorile europenității, dar mai ales tentația tradiționalismului, ce face trimitere la arta bizantină, cu care în definirea identităţii naționale se puteau distinge mai multe afinități. De la planimetrii tradiționale la decor plastic al paramentelor și ancadramentelor, elementul plastic decorativ, stilul neobizantin reflectă cel mai bine apartenența la mediul cultural răsăritean, chiar dacă anumite formulări au reiterat în perioada romantismului stilurile romanic și gotic.

Despre același stil național vorbesc și Ž. Škalamera ${ }^{\square}$ o introspecție a căutărilor repertoriului decorativ și stilistic sârbesc în arhitectura religioasă mai ales, dar cu vizibile tendințe și în arhitectura laică. Căutările teoretice ale stilului național sârbesc au beneficiat și de adițiile comparative ale lui B. Pantelić 6 , ce vede în tendințele stilistice adoptate în arhitectura sârbilor conotații naționaliste cu un spirit identitar puternic ce se reflectă în preferințe stilistice apusene (barocul) sau răsăritene, tradiționale (arta de factură bizantină), idei preluate din bibliografii interbelice ce făceau trimitere la aceleași coordonate.

Vârșețul se dezvoltă ca un centru bogat economic încă de la jumătatea secolului al XVIII-lea, devenind o adevărată oază de cultură, în care se vor contopi influențe din vestul catolic, dar și din estul ortodox. Europenizarea din perspectivă artistică, începe în acest secol al Luminilor, fiind vorba de o provincie a imperiului habsburgic ce devine un experiment reușit de implementare a politicilor culturale, religioase, economice și nu în ultimul rând, sociale prin colonizările ce au imprimat aspectul mozaicat al influențelor și modelelor de civilizație implementate.

\footnotetext{
${ }^{6}$ Profesorul universitar arhitect Cigler Gyozo i-a propus în 1900, la terminarea studiilor de la Budapesta să urmeze o carieră în învățământul superior, ofertă pusă în practică în calitate de asistent al profesorului Școlii Politehnice Regele Jozsef până în 1903, când propunerea edilului Timișoarei îi modifică aspirațiile și evoluția, documentele ce testă acest parcurs fiind publicate sub forma unor facsimile, pentru detalii vezi, I. Pintilie, Documente din arhive particulare contribuind la cunoaşterea unui arhitect timişorean de la începutul secolului XX-Laszlo Szekely, în Studii și comunicări, III, Museum Arad, 1996, pp. 202-224.
} 


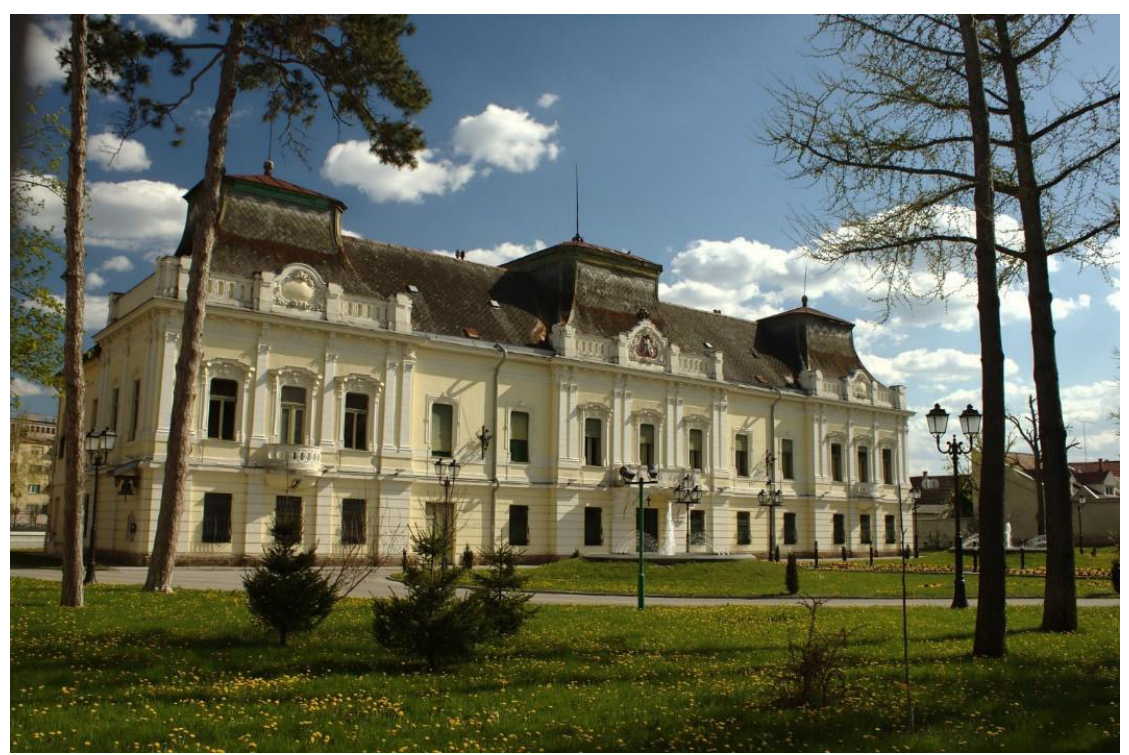

Foto 3. Palatul episcopal din Vârșeț (sursă online)

Palatul Episcopal din Vârşeţ a fost realizat între anii 1750 și 1757, debutul lucrărilor fiind motivat de mutarea reşedinţei Eparhiei Ortodoxe de la Caransebeș la Vârşeţ. Construcție monumentală cu evidente accente ale barocului vienez, palatul prezintă două niveluri și mansard, L. Szekely fiind arhitectul care transpune acest stil într-o construcție realizată la începutul secolului XX, prin valențe neobaroce cu accente clasicizante, afirmând puterea seculară a episcopilor prin recurența valorilor clasice. Planimetria consacrată acestui tip de edificiu, cu funcție rezidențială este cea dreptunghiulară cu parter înalt și piano nobile, acoperiș ce articulează în flancuri porțiuni mansardate, cu o curte interioară amplă ce dezvoltă masele prin adiționare, într-un perfect echilibru al volumetriilor dinamice specifice stilului. Accentuarea motivului central prin rezalitul subliniat de ferestre cu fronton arcuit segmentat, racordat prin volute la usciorii decorativi laterali, bosajul parterului ce amintește de rusticarea materialului pentru efecte plastice accentuate a palatelor din perioada renașterii italiene ${ }^{7}$, analogiile formale și stilistice fiind cele ce fac trimitere la formația academică a arhitectului L. Szekely, accentul functionalist predominând în detrimentul decorativismului. Dinamica fațadelor ritmate prin rezalitul cornișelor, prin alternarea suprafețelor plane cu cele dinamice, în care elemente plastice precum pilaștri, coloane, stâlpi generează spații pe care le definesc și accentuează, definind stilul eclectic al arhitectului ce cunoștea valorile stilistice ce pot fi îmbinate pentru a contura o sinteză de influențe, evocând totodată contopirile ce formează limbajul formal și plastic al arhitecturii perioadei în cauză.

\footnotetext{
${ }^{7}$ Gabriel Szekely, Arhitectura orașelor libere regești Timișoara și Arad, în Istoria Banatului (V. Neumann coordonator), Ed. Academiei, București, 2016, p.224.
} 
Construit în perioada episcopatului lui Jovan Georgijević (elev al patriarhului Arsenije IV de Sakabent) pentru a servi nevoilor arhierești după mutarea sediului eparhial de la Caransebeș, la Vârșeț, palatului episcopal din Vârșeț i s-a adăugat și o capelă închinată Sfinților arhangheli Mihail și Gavril, mobilată cu un iconostas pictat între anii 1761 și 1765. Intervenția arhitectului Szekely este consemnată în anul 1905, când se amplifică spațial și se adaugă decorații în spiritual istorist al vremii, fără a altera aspectul inițial al edificiului.

Considerațiile privind evoluția celor două monumente de arhitectură palațială se situează între două coordonate: cea a asimilării și cea a identității, între aceste două repere căutăm sensul manifestărilor în perioade istorice diferite, fiecare cu evoluții specifice, cu formări și receptări ale modelelor europene ce conturează în istoria Banatului un episod al istoriei arhitecturii europene. Orientări stilistice, opțiuni arhitecturale, paralele culturale, toate se subsumează afirmării naționale în aceste două orașe moderne ale Banatului, studiile de caz introductive fiind dovezi elocvente ale alinierii la evoluția europenității, chiar dacă curentele artistice ilustrate sunt faze târzii ce transpun sinteze ale stilurilor și anticipează mișcările novatoare.

\section{Bibliografie}

Merenyi Ferencz, Magyar Epiteszek Adatgyujtemeny, 1890-1918. Budapesta, 1955. Aleksandar Kadijević, Traženja srpskog nacionalnog stila u arhitekturi Banata (I): Preobraženska crkva u Pančevu.Timișoara: Analele Banatului, Serie nouă, Artă, vol. IV, 1999-2002, pp. 57-68; Idem, Jedan vek trženija nacionalnog stila u srpskoj arhitekturi (sredine XIX-sredine XX veka). Beograd, 1997.

Ileana Pintilie, Documente din arhive particulare contribuind la cunoașterea unui arhitect timişorean de la începutul secolului XX-Laszlo Szekely.Arad:Studii și comunicări, III, 1996.

Ž. Škalamera, Obnova "srpskog stila" u arhitekturii. Novi Sad: Zbornik za likovne umetnosti Matice srpske, 5, 1969.

Gabriel Szekely, Arhitectura orașelor libere regești Timișoara și Arad. București: Istoria Banatului (V. Neumann coordonator), Ed. Academiei, 2016.

B. Pantelić, Nationalism and Architecture. The Creation of a national Style ibn Serbian Architecture and its political implications. Novi sad: Journal of the Society of Architectural Historians, 56, 1997.

M. Porumb, M. Vlăsceanu, Arhitectura din Transilvania și Banat în secolul XVIII. București: Arta din România. Din preistorie în contemporaneitate. (M. Porumb, R. Theodorescu editori)., 2018.

M.Vlăsceanu, Modele identitare ortodoxe în arhitectura barocă din Banat.Timișoara: Život posvećen traganju za etničkim identitetom - volum omagial dedicat Profesorului univ.dr. Mihai Radan, Ed. Universităţii de Vest,2019. 
Mihaela Vlăsceanu

\title{
ARCHITECTURAL SOLUTIONS IN TIMISTOARA AND VÂRȘET $\left(\mathbf{1 8}^{\text {th }}-\mathbf{2 0}^{\text {th }}\right.$ Centuries). CASE STUDY: THE ORTHODOX BISHOPRIC SERBIAN PALACES
}

\begin{abstract}
Summary
Being monuments endowed with ideological dimension, the Orthodox Bishopric Serbijan palaces from Vârșeț and Timișoara present interesting stylistical evolutions, from 18th century's late Baroque to $20^{\text {th }}$ Century Viennese Secession. Symbolizing the power of Orthodox Church rulers, these constructions adopted the Catholic Baroque style, crossed through the Romantic period with the rebirth of neoclassical values and ended in what was configured at the beginning of the $20^{\text {th }}$ century as the closure with the academic dimension and the introduction of the Secession style. The hypothesis of the paper states the importance of European artistic values in defining identity, as the case of these two palaces with their evolution, an evolution that culminated in synthesis. Art patronage from this perspective has implications for the evolution, as such, the two monuments illustrate Serbian religious authority and its reaction to the modern art. In this case the palaces stand as hallmarks for the ecclesiastical architecture of the Banat, a focal point in the general phenomenon.
\end{abstract}

Key words: Bishopric Serbijan palaces, Vârșeț, Timișoara, baroc, Secession, Laszlo Szekely 